\title{
Evaluation of the Lateral Forces Acting on Stabilizing Piles Considering the Resistance of the Lower Zone of A Landslide in the Three Gorges Reservoir, China
}

\author{
Shuangjie Yan ${ }^{1}$, Yang Wang ${ }^{1, *}$, Hao Du ${ }^{1}$, Le Yu ${ }^{1}$ and Shiying Zheng ${ }^{2}$ \\ ${ }^{1}$ Faculty of Engineering, China University of Geosciences, Wuhan 430074, China \\ ${ }^{2}$ Department of Civil and Structural Engineering, The University of Sheffield, Sheffield, South Yorkshire, S10 2TN, United Kingdom
}

Received 1 September 2016; Accepted 15 November 2016

\begin{abstract}
Evaluation of lateral forces acting on the stabilizing pile above the slip mass can directly influence the accuracy of calculating the internal force of a pile, thus affecting the rationality of the design of stabilizing piles. A novel method to accurately evaluate these lateral forces on the basis of the limit equilibrium method of slices was proposed in this study. The method was used to estimate the lateral forces acting on the stabilizing piles above the slip surface of a landslide. A landslide was divided into upper and lower sections, and the distinct target safety factors of the two sections were used to determine the lateral forces. The maximum value of the lower lateral force was determined when a state of limit equilibrium was reached. A case study was conducted to compare the lateral forces obtained using the traditional and proposed methods. Results demonstrate that the lower lateral resistance forces account for $75.1 \%, 43.5 \%$, and $19.6 \%$ of the upper lateral forces in the three selected cases. These findings indicate a massive resistance force in the lower part and the considerable effect of seepage of groundwater on the lateral forces. The proposed method provides a good prospect to optimize the design of stabilizing piles.
\end{abstract}

Keywords: Landslide, Stabilizing pile, Upper lateral force, Lower lateral force

\section{Introduction}

With respect to available measures of stabilizing the slope, anchor cable, slope flattening, stabilizing piles, retaining wall, shotcrete, and wire mesh are popular in engineering practices [1]. Due to well performance of anti-sliding, stabilizing piles are extensively used for landslide treatment, and the application of stabilizing piles has attracted much attention [2,3]. Therefore, the design of stabilizing piles is an interesting and meaningful research topic. Previous studies showed that limit equilibrium and numerical methods are popular techniques for designing stabilizing piles $[4,5]$. The limit equilibrium method is a simple and useful method frequently used for geological disaster prevention in the Three Gorges Reservoir (TGR) and other geotechnical designs.

In the existing literatures, the emphasis of stabilizing pile design mainly includes evaluation of lateral forces acting on stabilizing piles and distribution of landslide-thrust and resistance of slip mass [6,7].

Evaluation of lateral forces acting on stabilizing piles is an indispensable step during the designing of stabilizing piles. This process has become a great challenge to engineers because of numerous influencing factors, such as soil arching, pore pressure, and seepage of groundwater [8, 9]. In addition, the stability of slip mass on two sides of the piles determines the thrust force of the upper slip mass and resistance force of the lower slip mass. Thus, this stability should be considered when the lateral forces are calculated,

- E-mail address: wangyangcug@126.com

ISSN: 1791-2377 @ 2016 Eastern Macedonia and Thrace Institute of Technology. All rights reserved. and the lateral force of the lower slip mass cannot be neglected when the lower slip mass remains stable.

Based on the above analysis, this study examines a core problem in the design of stabilizing piles. Subsequently, the effects of pore water pressure and seepage of groundwater are also considered.

\section{State of the art}

A reinforced concrete pile transmits the driving force of a sliding mass that acts on the pile segment above the slip surface to the bedrock or stable layers. Piles have become extensively used and demonstrated as an effective means against landslide failures. Stabilizing piles presently constitute $78 \%$ of all preventive measures for landslides in the Wanzhou District of the TGR, China [10].

Accurate estimation of the lateral forces above slip surfaces is important to effectively design stabilizing piles.

The majority of analytical methods for lateral forces are based on soil movement and the interaction between the pile and surrounding soils. Ito and Matsui [11] developed the plastic state theory, in which the soil around piles is assumed to be in a plastic state. The plastic deformation theory satisfies Mohr-Coulomb's yield criterion. The plastic flow theory regards soil as a visco-plastic solid, and two vertical sliding surfaces occur along lines that enclose angles of $\left(45+\frac{\varphi}{2}\right)$ with the direction of soil movement. The lateral forces depend on the strength properties of the soil, overburden pressure, and space between piles relative to their diameters. The friction circle method extended by Hassiotis et al. [12] defines a new stability number that 
includes the pile reaction to determine the modified critical surface and factor of safety (FOS) of the reinforced slope. However, this method is limited to circular slip surfaces and homogeneous soil profiles. The mobilized driving soil-pile pressure per unit length of the pile above the slip surface can be determined using the strain wedge model. The geometry of the compound passive wedge depends on the properties and number of soil types in the soil profile and the global equilibrium between the soil layers and loaded pile [13, 14]. The effect of soil arching caused by the installation of the pile developed by Liang and Zeng [15] can be incorporated into the traditional method of slices to determine the lateral forces. This process uses a reduction factor obtained from load transfer curves generated by finite element analysis. Lateral loads and soil reactions vary with oil type [16]. The lateral soil pressures change with the evolution of a landslide. Vertical variations in the soil pressure above anti-sliding piles conform to a sigmoidal curve during the initial deformation. The variation becomes more parabolic during uniform deformation and fully parabolic during accelerated deformation [17].

The lateral load-transfer curve ( $\mathrm{p}-\mathrm{y}$ curve) method has been used to estimate the ultimate lateral soil pressure $\left(P_{u}\right)$ acting on a pile segment above the slip surface. The $\mathrm{p}-\mathrm{y}$ curve can be modeled as a beam resting on nonlinear soil spring supports, and the value for each pile in a group can be evaluated by considering the group interaction factor and Rankine's passive pressure. In clay soils, the ultimate lateral pressure is related to the undrained shear strength and lateral capacity factor [18]. A series of laboratory model tests using soft clay have been conducted to determine the ultimate soil pressure acting on a pile shaft [19].

Finite element and finite difference methods have become increasingly popular. These methods provide the ability to model complex geometries and soil-structure interaction phenomena, such as pile-group effects. Moreover, these methods can model the three dimensionality of a problem and well-capture soil and pile nonlinearities [20-23]

Limit equilibrium analysis in conjunction with the method of slices is the most frequently used method for evaluating lateral forces. This technique can accommodate complex slope geometries with variable soil properties, pore-water pressure conditions, different shapes of slip surfaces, and influence of external boundary loads. A conventional simplified Bishop slip circle approach can be employed to analyze the slope stability and the resisting moment generated by a pile at the depth of the sliding surface. The method can account for the effects of the soil arching mechanism [24]. Zhou et al. [25] considered the influence of reservoir water fluctuations, rainfall amounts, and shear strength of a slip surface on the lateral force. A PC-based program M-UASLOPE allows the handling of an arching-induced reduction in the driving forces, complex slope geometries, soil profiles and ground water conditions [26].

A landslide can be divided into upper and lower zones depending on the locations of the stabilizing piles (Fig. 1). Hence, the lateral forces acting on the stabilizing piles also comprised upper and lower lateral forces. These existing methods have been successfully applied to estimate upper lateral forces, while a few studies have examined the lower lateral forces. For partially submerged landslides with piles, the lower lateral forces dynamically change because of fluctuations in the river water levels and phreatic surface. The lower lateral forces should be estimated to better understand the practical use of piles in stabilizing partially submerged landslide. This study proposes a method to estimate the lateral forces acting on a stabilizing pile segment above a slip surface by considering the resistance of the lower zone. This approach allows the upper and lower slide masses to possess different FOSs. The method is based on the limit equilibrium method of slices and considers the effects of the seepage forces of groundwater and fluctuations in the river water levels on the lateral forces.

The remainder of this study is organized as follows. Section 3 establishes the mechanical model and proposes the method for calculating the lateral forces. Section 4 discusses the applicability of the method through case studies. Section 5 summarizes the conclusions.

\section{Methodology}

\subsection{Different Values of the Factors of Safety of the Upper and Lower Zones}

\subsubsection{Two landslide zones with piles}

A typical cross section of a landslide with a row of stabilizing piles is shown in Fig. 1. The two zones of the landslide, namely, the upper and lower slide masses, are bounded by the stabilizing pile. Additionally, installation of the stabilizing pile results in the replacement of the interactive forces between the upper and lower slide masses by the lateral forces acting on the stabilizing pile. The lateral forces consist of two parts. One part is the interactive force between the pile and the upper slide mass. This force, which is the upper lateral force in this study, acts on the upslope face of the pile $\left(E_{u}\right)$. The other part is the interactive force between the pile and the lower slide mass. This force, which is the lower lateral force in this study, acts on the downslope face of the pile $\left(E_{u}\right) \cdot E_{u}$ is an active sliding force and assumed to act on the pile parallel to the slice base. By contrast, is a type of resistance force and assumed to act on horizontally, because it is formed by the horizontal downslope deformation of the pile. The amount of these forces is dependent on the stability of slip mass on two sides of the piles. The upper lateral force increases as the upper slide mass becomes more unstable. The lower lateral force decreases as the lower slide mass becomes more unstable.

The pile is used to allow the upper slide mass to meet a prescribed target FOS by transmitting the driving force of the upper slide mass that acts on the pile segment above the slip surface to the bedrock and the lower slide mass. However, the stability of the lower slide mass cannot be ensured by the pile. Therefore, we posit that the upper and lower slide masses have different FOS values after the installation of piles in the landslide.

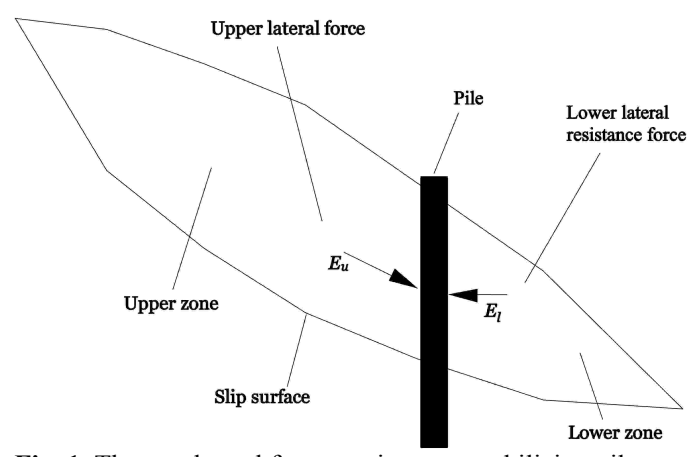

Fig. 1. The two lateral forces acting on a stabilizing pile 


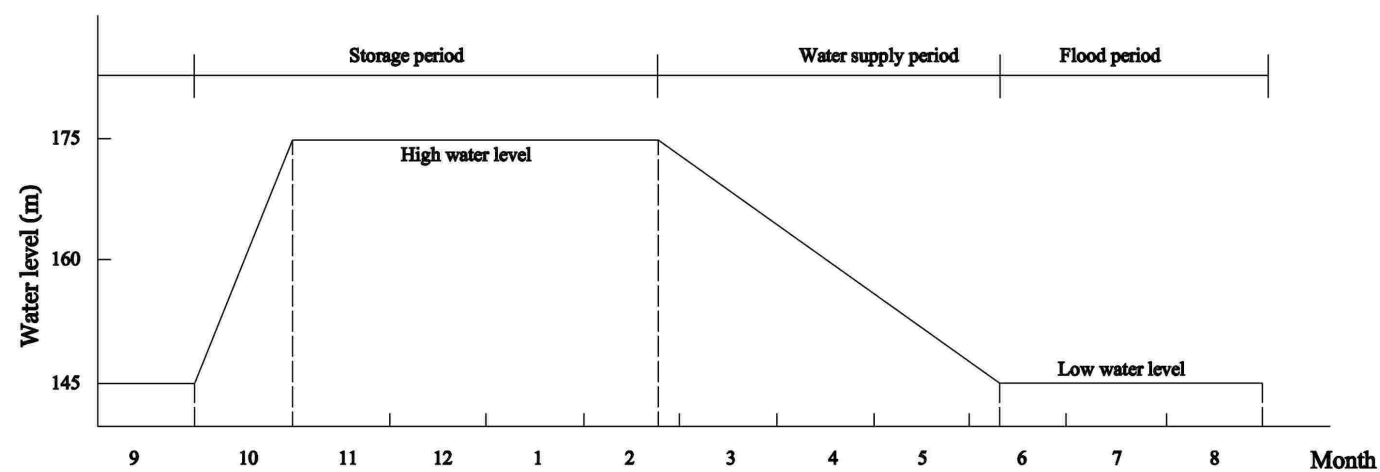

Fig. 2. Water level of the TGR

Table 1. Values of the target FOS for the landslide stabilization design

\begin{tabular}{c|c|c|c|c}
$\begin{array}{c}\text { Landslide stabilization } \\
\text { safety rank }\end{array}$ & $\begin{array}{c}\text { First } \\
\text { class }\end{array}$ & $\begin{array}{c}\text { Second } \\
\text { class }\end{array}$ & $\begin{array}{c}\text { Third } \\
\text { class }\end{array}$ & Reservoir water level and rainfall \\
\hline & 1.25 & 1.2 & 1.15 & Case 1: 175 m water level + rainfall amount in the storage period \\
Value of the target FOS & 1.25 & 1.2 & 1.15 & Case 2: 145 m water level + rainfall amount in the flood period \\
& 1.20 & 1.15 & 1.10 & Case 3: 175 m water level dropdown to 145 m water table + rainfall amount \\
& & in the water supply period
\end{tabular}

Table 2. Landslide stabilization safety rank and hazard-affected elements

\begin{tabular}{c|l|l|l}
\hline Hazard-affected elements & \multicolumn{3}{c}{ Landslide stabilization safety rank } \\
\cline { 2 - 4 } & First class & Second class & Third class \\
\hline Number of people affected & $>2000$ & $300-2000$ & $<300$ \\
Economic losses after failure (million \$) & $>16$ & $3-16$ & $<3$ \\
\hline
\end{tabular}

Table 3. Landslide stabilization safety rank and rainfall condition

\begin{tabular}{c|c}
\hline Landslide stabilization safety rank & Return period of rainfall (y) \\
\hline First class & 50 \\
Second class & 20 \\
Third class & 10 \\
\hline
\end{tabular}

\subsubsection{Target factor of safety of the upper slide mass}

The water level of the TGR fluctuates between $145 \mathrm{~m}$ and $175 \mathrm{~m}$ annually (Fig. 2). The reservoir water level is usually sustained at 145 and $175 \mathrm{~m}$ during the flooding and storage periods, respectively.

The target FOS of the upper slide mass of the landslide in the TGR mainly depends on the landslide stabilization rank, reservoir water level, and rainfall (Table 1) [27]. The landslide stabilization safety rank is graded according to the number of people who would be affected by the landslide and economic losses after failure (Table 2). The target FOS should allow for the return period of rainfall (Table 3).

\subsubsection{Target FOS of the lower slide mass}

The top elevation of the stabilizing pile is slightly higher than $175 \mathrm{~m}$, because the water level of the TGR fluctuates between $145 \mathrm{~m}$ and $175 \mathrm{~m}$. During storage period, the stabilizing piles are near the reservoir water when the water level is sustained at $175 \mathrm{~m}$, which causes the lower slide mass to become completely or partially submerged (Fig. 3).

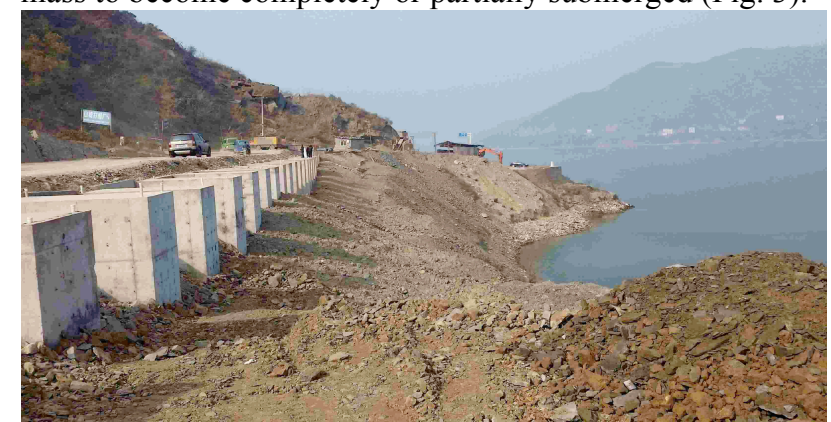

Fig. 3. Partially submerged lower slide mass of the Feibaocao landslide in Zigui County, TGR, China
The stability of the lower slide mass dynamically changes with the annual rise and drawdown of the reservoir water level. The impoundment of the reservoir decreases the shear strength of the slip surface below the water level. During the water supply period, the reservoir water level drops from $175 \mathrm{~m}$ to $145 \mathrm{~m}$, and the water pressure acting on the lower slide mass disappears. The water level drops quickly, but the pore water pressure of the sliding mass dissipates slowly. Thus, the drop in water level reduces the stability of the lower slide mass.

The lower lateral resistant force $E_{l}$ also dynamically varies with the stability of the lower slide mass. The lower slide mass is more stable, $E_{l}$ is greater, and the reaction of $E_{l}$ that acts on the lower slide mass will be greater. When the reaction causes the lower slide mass to meet a state of limit equilibrium, $E_{l}$ will reach a maximum value, which is the target lower lateral resistance force in this study. Therefore, we hypothesize that the target FOS of the lower slide mass is equal to 1.0. If the lower slide mass is unstable, we presume that $E_{l}$ is zero.

\subsection{Lateral Forces Acting on a Stabilizing Pile}

\subsubsection{Forces acting on a type slice}

The lateral forces acting on the stabilizing piles are calculated using the limit equilibrium method, and the slice method is used to analyze the forces acting on the slices (Fig. 4). The slice number of the lower slide mass is $n$, and the number of the upper slide mass is $m$. The base friction of the 
landslide is the main anti-slide force (Fig. 5). The driving forces mainly include gravity and seepage force, which can be expressed as follows:

$$
\begin{aligned}
& P_{i}=V_{i d} r_{w} \sin \alpha_{i} \\
& W_{i}=V_{i u} r+V_{i d} r^{\prime}
\end{aligned}
$$

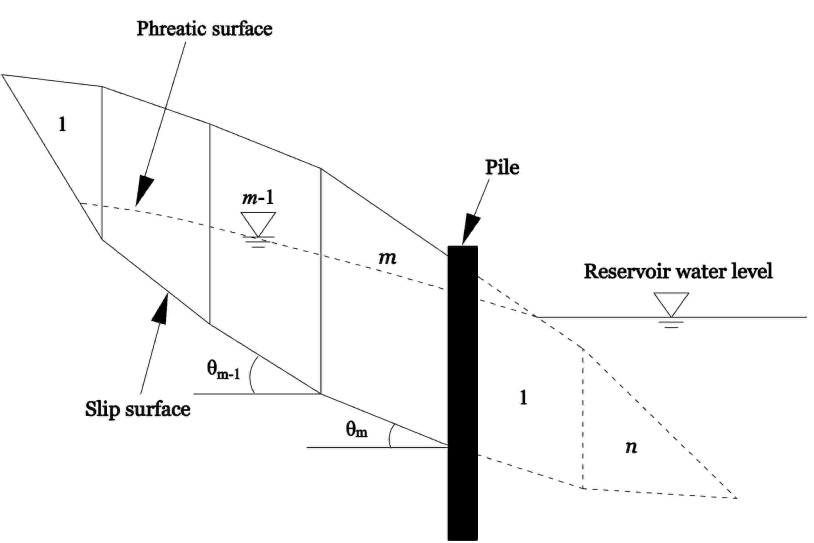

Fig. 4. Vertical slices of a piled landslide

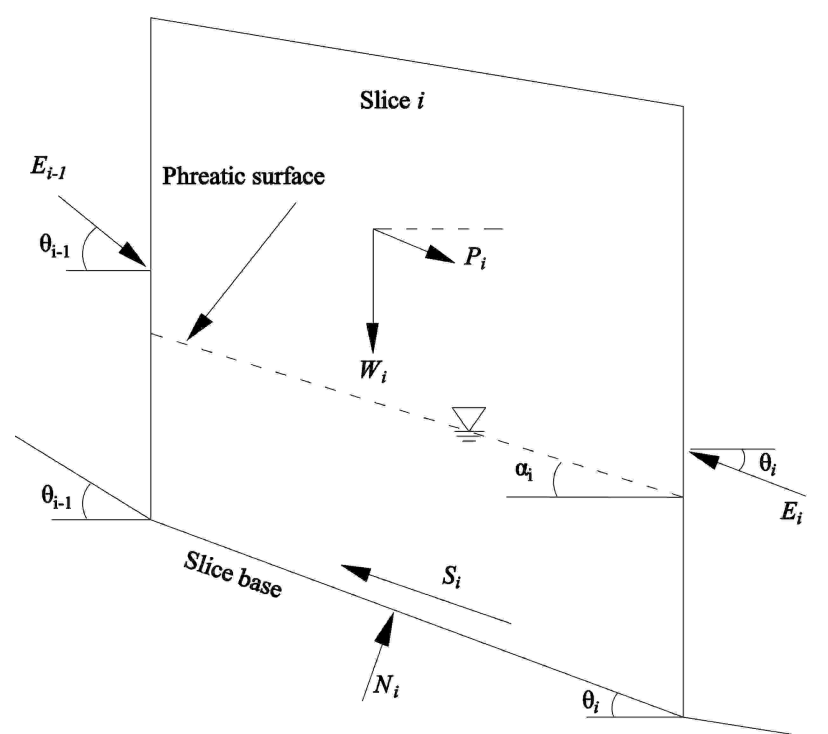

Fig. 5. Forces acting on a slice

where $P_{i}$ is the seepage force of slice $i, V_{i d}$ is the volume of slice $i$ below the phreatic surface, $\gamma_{w}$ is the unit weight of water, $\alpha_{i}$ is the inclination of the phreatic surface in slice $i$, $W_{i}$ is the weight of slice $i, V_{i u}$ is the volume of slice $i$ above the phreatic surface, $\gamma$ is the unit weight of soil, and $\gamma^{\prime}$ is the buoyant unit weight of the soil.

\subsubsection{Mobilized shear strength along the slip surface}

The FOS against shear failure is an important parameter to analyze landslide stability because of the uncertainties in the strengths of the landslide materials and pore pressure distributions. The FOS $(F)$ is defined as the ratio of the shear strength along the slip surface $\left(\boldsymbol{\tau}_{\mathrm{f}}\right)$ to the shear stress $(\boldsymbol{\tau})$ required to maintain the slope in a state of limit equilibrium, as follows:

$$
F=\frac{\tau_{\mathrm{f}}}{\tau}
$$

The mobilized shear strength along the slip surface based on the Mohr-Coulomb yield criterion is as follows [28]:

$$
S=\frac{c \cdot l+N \tan \varphi}{F}
$$

Where $S$ is the mobilized shear strength along the slip surface, $l$ is the length of the slip surface, $N$ is the normal force of the slip surface, $c$ is the cohesion of the slip surface, and $\varphi$ is the friction angle of the slip surface.

\subsubsection{Determination of the upper lateral force}

Piles can provide the lateral resisting forces needed to increase the FOS of the upper slide mass to the target value. The upper lateral forces are analyzed based on a target FOS using the limit equilibrium method of slices. Several assumptions are applied to this approach. (1) The upper slide mass is divided into a series of vertical slices. (2) Each slice is assumed to be rigid. (3) The FOS is considered to be identical for all slices. (4) The resultant of the interslice force $\left(E_{i}\right)$ is assumed to incline at an angle parallel to the slice base. (5) If the resultant of the interslice force is negative, the value is assumed to be zero.

All forces can be resolved into components parallel or perpendicular to the slice base. The components of the forces acting on the slice are in equilibrium when the following equations are satisfied:

$$
\begin{aligned}
& W_{i} \cos \theta_{i}+P_{i} \sin \left(\alpha_{i}-\theta_{i}\right)+E_{i-1} \sin \left(\theta_{i-1}-\theta_{i}\right)-N_{i}=0 \\
& W_{i} \sin \theta_{i}+P_{i} \cos \left(\alpha_{i}-\theta_{i}\right)+E_{i-1} \cos \left(\theta_{i-1}-\theta_{i}\right)-S_{i}-E_{i}=0
\end{aligned}
$$

where $E_{i-1}$ is the interslice force of slice $i-1$ acting on slice $i$ at the vertical boundary, $E_{i}$ is the interslice force of slice $i$ acting on slice $i+1$ at the vertical boundary, $N_{i}$ is the normal force at the base of slice $i$, and $\theta_{i}$ is the inclination of the slice base of slice $i$.

Substituting Eq. (5) into Eq. (4), the following equations can be obtained:

$$
S_{i}=R_{i}+\frac{E_{i-1} \sin \left(\theta_{i-1}-\theta_{i}\right) \tan \varphi_{i}}{F_{1}}
$$

$R_{i}=\left[W_{i} \cos \theta_{i}+P_{i} \sin \left(\alpha_{i}-\theta_{i}\right)\right] \frac{\tan \varphi_{i}}{F_{1}}+\frac{c_{i} \cdot l_{i}}{F_{1}}$

Where $F_{l}$ is the target FOS of the upper slide mass.

The following expressions can be derived by substituting Eq. (7) into Eq. (6):

$$
\begin{aligned}
& E_{i}=T_{i}-R_{i}+E_{i-1} \psi_{i-1} \\
& T_{i}=W_{i} \sin \theta_{i}+P_{i} \cos \left(\alpha_{i}-\theta_{i}\right) \\
& \psi_{i-1}=\cos \left(\theta_{i-1}-\theta_{i}\right)-\frac{\sin \left(\theta_{i-1}-\theta_{i}\right) \tan \varphi_{i}}{F_{1}}
\end{aligned}
$$

Eq. (9) can be applied to any vertical slice of landslide, as follows:

$$
E_{1}=T_{1}-R_{1}
$$


$E_{2}=T_{2}-R_{2}+\left(T_{1}-R_{1}\right) \psi_{1}$

$E_{3}=T_{3}-R_{3}+\left(T_{2}-R_{2}\right) \psi_{2}+\left(T_{1}-R_{1}\right) \psi_{2} \psi_{1}$

$E_{m}=\left[T_{m}+\sum_{j=1}^{m-1}\left(T_{j} \prod_{k=j}^{m-1} \psi_{k}\right)\right]-\left[R_{m}+\sum_{j=1}^{m-1}\left(R_{j} \prod_{k=j}^{m-1} \psi_{k}\right)\right]$

If the stabilizing pile is installed at the lower boundary of slice $\mathrm{m}$ (Fig. 1), the interslice force between slice $\mathrm{m}$ and slice $(\mathrm{m}+1)$ can be used to calculate the upper lateral force $\left(E_{u}\right) \cdot E_{u}$ is an equal and opposite reaction of $E_{m}$, as follows:

$E_{u}=E_{m}$

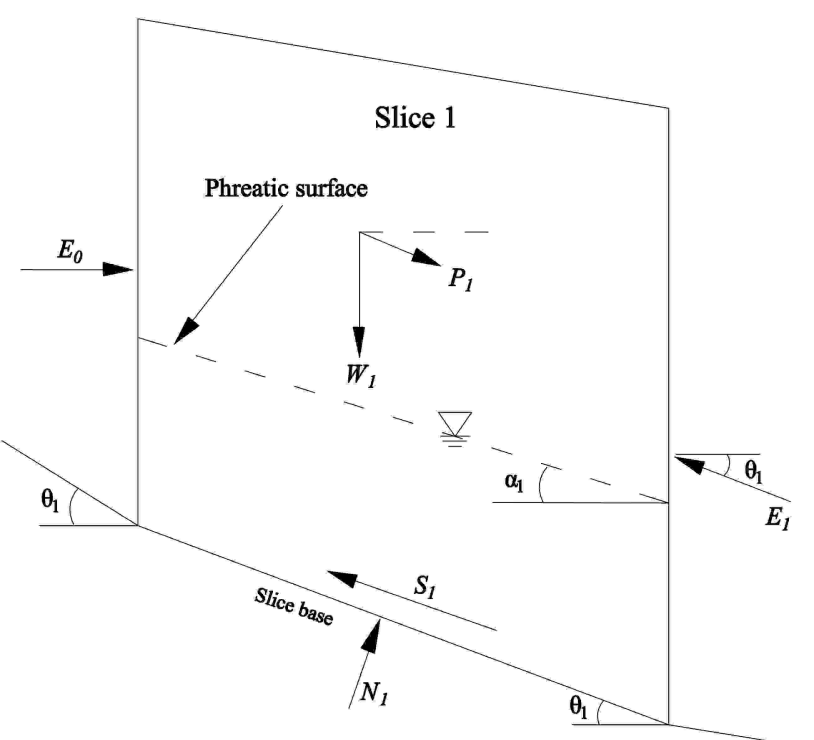

Fig. 6. Forces acting on the first slice of the lower slide mass

\subsubsection{Determination of the lower lateral resistance force} All forces acting on the first slice can also be resolved parallel or perpendicular to the slice base (Fig. 6). The components of the forces acting on the slice are in equilibrium when the following conditions are satisfied:

$$
\begin{gathered}
W_{1} \cos \theta_{1}+P_{1} \sin \left(\alpha_{1}-\theta_{1}\right)-E_{0} \sin \theta_{1}-N_{1}=0 \\
W_{1} \sin \theta_{1}+P_{1} \cos \left(\alpha_{1}-\theta_{1}\right)+E_{0} \cos \theta_{1}-S_{1}-E_{1}=0
\end{gathered}
$$

The following equations are obtained by substituting Eq. (14) into Eq. (4):

$$
\begin{aligned}
& S_{1}=R_{1}-\frac{E_{0} \sin \theta_{1} \tan \varphi_{1}}{F_{2}} \\
& R_{1}=\left[W_{1} \cos \theta_{1}+P_{1} \sin \left(\alpha_{1}-\theta_{1}\right)\right] \frac{\tan \varphi_{1}}{F_{2}}+\frac{c_{1} \cdot l_{1}}{F_{2}}
\end{aligned}
$$

Where $F_{2}$ is the target FOS of the upper slide mass.

The following expressions can be derived by substituting Eq. (16) into Eq. (15):

$$
\begin{aligned}
& E_{1}=T_{1}-R_{1}+E_{0}\left(\cos \theta_{1}-\frac{\sin \theta_{1} \tan \varphi_{1}}{F_{2}}\right) \\
& E_{1}=T_{1}-R_{1}+E_{0} \psi_{0}
\end{aligned}
$$

$$
T_{1}=W_{1} \sin \theta_{1}+P_{1} \cos \left(\alpha_{1}-\theta_{1}\right)
$$

$\psi_{0}=\cos \theta_{1}-\frac{\sin \theta_{1} \tan \varphi_{1}}{F_{2}}$

When $i$ is greater than $1, E_{i}$ acting on any slice of the lower slide mass have the same expressions as those of the upper slide mass, as follows:

$$
\begin{gathered}
E_{2}=T_{2}-R_{2}+\left(T_{1}-R_{1}\right) \psi_{1}+E_{0} \psi_{1} \psi_{0} \\
E_{3}=T_{3}-R_{3}+\left(T_{2}-R_{2}\right) \psi_{2}+\left(T_{1}-R_{1}\right) \psi_{2} \psi_{1}+E_{0} \psi_{2} \psi_{1} \psi_{0} \\
\vdots \\
E_{n}=\left[T_{n}+\sum_{j=1}^{n-1}\left(T_{j} \prod_{k=j}^{n-1} \psi_{k}\right)\right]-\left[R_{n}+\sum_{j=1}^{n-1}\left(R_{j} \prod_{k=j}^{n-1} \psi_{k}\right)\right]+E_{0} \prod_{j=0}^{n-1} \psi_{j}
\end{gathered}
$$

When the target FOS of the lower slide mass is equal to $1.0, E_{l}$ reaches a maximum value, which is the target value in this study. When the lower slide mass is maintained in a state of limit equilibrium, $E_{n}$ is zero, and $E_{0}$ can be calculated as follows:

$$
E_{0}=\frac{\left[R_{n}+\sum_{j=1}^{n-1}\left(R_{j} \prod_{k=j}^{n-1} \psi_{k}\right)\right]-\left[T_{n}+\sum_{j=1}^{n-1}\left(T_{j} \prod_{k=j}^{n-1} \psi_{k}\right)\right]}{\prod_{j=0}^{n-1} \psi_{j}}
$$

The lower lateral resistance force $\left(E_{l}\right)$ is an equal and opposite reaction of $E_{0}$, as follows:

$$
E_{l}=E_{0}
$$

\section{Result Analysis and Discussion}

\subsection{Engineering geological conditions of the Xiatudiling landslide}

The Xiatudiling landslide is located in Shuitianba, Zigui County, Hubei Province, China, on the south bank of the Yuanshui River, which is a branch of the Yangtze River (Fig. 7). This area is approximately $10 \mathrm{~km}$ northwest of the town of Guizhou. The landslide is approximately $170 \mathrm{~m}$ long and $14 \mathrm{~m}$ thick and has a volume of $25 \times 10^{4} \mathrm{~m}^{3}$. A small shallow gully is considered to be its right boundary. The middle and rear parts of the landslide are 70 and $150 \mathrm{~m}$ wide, respectively, and the front part had largest width $(210 \mathrm{~m})$. The elevations of the top and toe of the landslide are 205 and $155 \mathrm{~m}$, respectively (Figs. 8 and 9).

The Xiatudiling landslide consists of loose rubble soil with $15 \%-40 \%$ clay content. The rubble particles, which consist of sandstone and mudstone, have maximum and minimum diameters of approximately 1.0 and $0.2 \mathrm{~m}$, respectively. The slip surface is mainly formed in a strongly weathered mudstone. The slip surface material exposed in the vertical shaft is reddish-brown plastic clay, whereas purple clay soil with rubble is found at the toe of the slip surface. Several scratches on the slip surface have an average depth of $0.001-0.003 \mathrm{~m}$ and an average width of $0.01 \mathrm{~m}$. The slip surface has a dip direction of $342^{\circ}$ and a dip angle of $8^{\circ}$. The bedrock of the landslide is formed in the 
Penglaizhen Formation of the Jurassic Period and mainly comprised purple mudstone, purple pelitic siltstone, and grey feldspar-quartz sandstone.

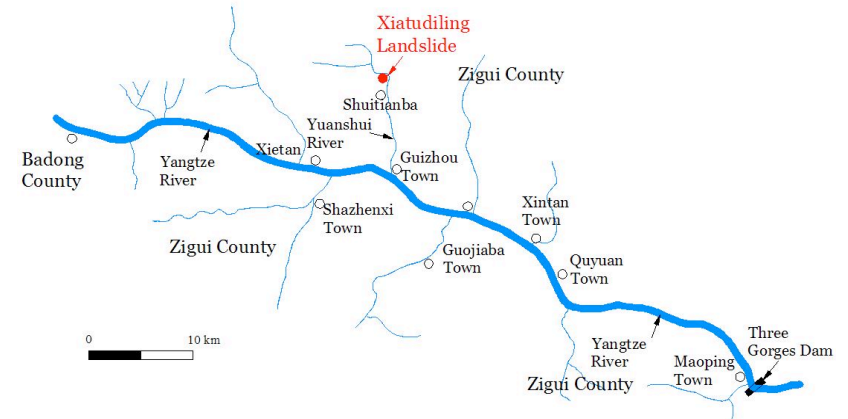

Fig. 7. Location of the Xiatudiling landslide

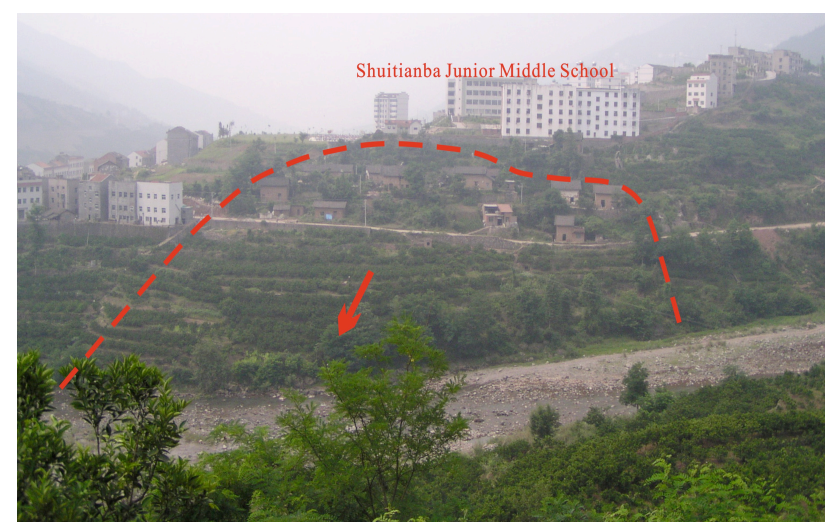

Fig. 8. View of the Xiatudiling landslide

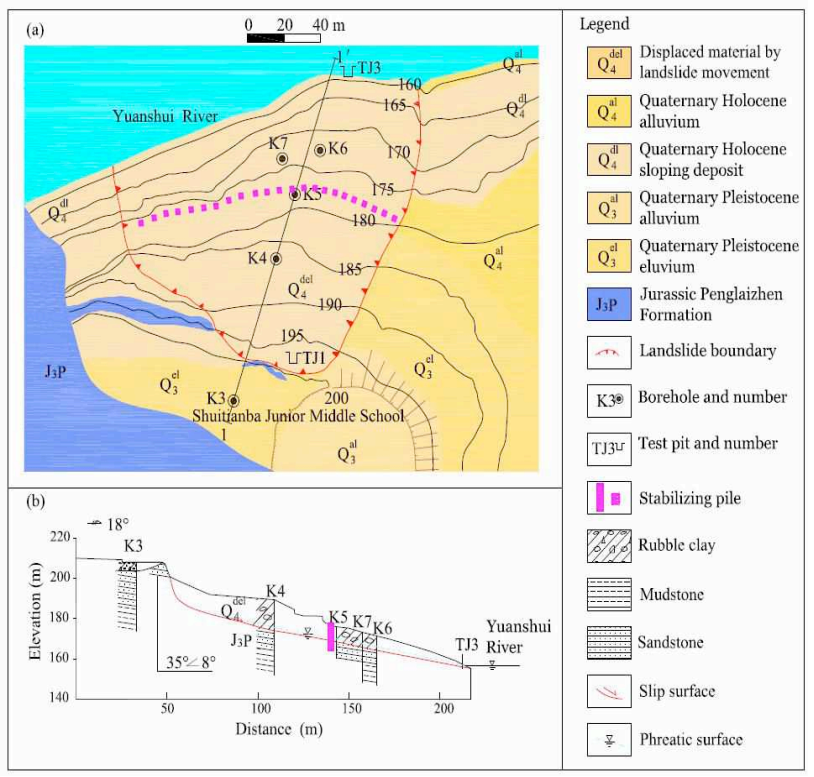

Fig. 9. (a) Geological plan of the Xiatudiling landslide and (b)geological profile of Section 1-1' of the Xiatudiling landslide

\subsection{Reservoir water level and rainfall conditions for the lateral forces}

The landslide affected 1800 people, which included 65 people who lived in 14 houses, while the rest lived in the Shuitianba Junior Middle School dormitories. The landslide stabilization safety rank belongs to the second class (Table 2). The return period of rainfall for this landslide is 20 years, and a Log-Pearson Type 3 Distribution [29, 30] was used for the rainfall frequencies and accumulated rainfall amounts based on rainfall data for the past 50 years for Zigui County (Table 4). The combined effect of rainfall and reservoir water level on the changes in the subsurface flow was simulated using the SEEP/W module of the Geo-Studio software program of Itasca Consulting Group, Inc. (Fig. 10).

Table 4. Accumulated rainfall amount over 5 days

\begin{tabular}{c|c|c|c}
\hline \multirow{2}{*}{$\begin{array}{c}\text { Return period of } \\
\text { rainfall (a) }\end{array}$} & \multicolumn{3}{|c}{$\begin{array}{c}\text { Accumulated rainfall amount in } 5 \text { days } \\
(\mathbf{m m})\end{array}$} \\
\cline { 2 - 4 } & $\begin{array}{c}\text { Storage } \\
\text { period }\end{array}$ & $\begin{array}{c}\text { Water supply } \\
\text { period }\end{array}$ & $\begin{array}{c}\text { Flood } \\
\text { period }\end{array}$ \\
\hline 20 & 130 & 138 & 210 \\
\hline
\end{tabular}
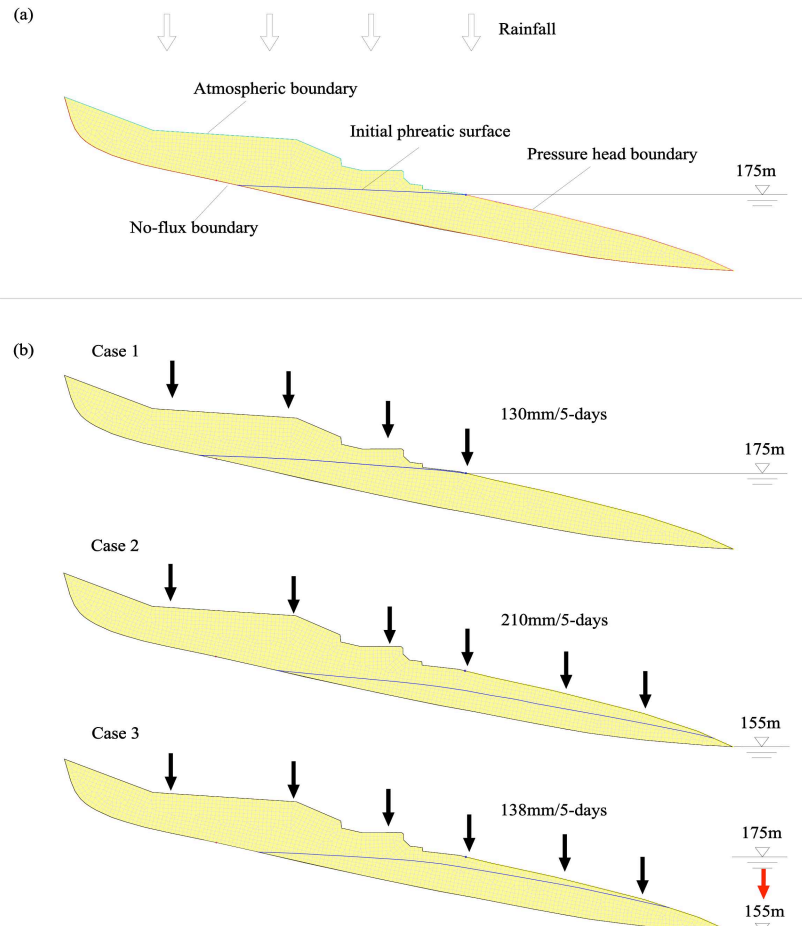

Fig. 10. (a) Meshes of the numerical simulation model and the initial phreatic surface and boundary conditions for SEEP/W analysis. (b) The phreatic surface with different rainfall and reservoir water levels computed by the SEEP/W model

\subsection{Lateral forces of the Xiatudiling landslide with piles}

The Xiatudiling landslide was divided into 40 vertical slices based on the ground surface morphology and slip surface shape, and the stabilizing pile was located at the lower boundary of slice 22 (Fig. 11). The cohesion of the slip surface was $10 \mathrm{kPa}$, and the friction angle was $12.2^{\circ}$. The dry and saturated unit weights of the landslide material were 21.5 and $23.5 \mathrm{kN} / \mathrm{m}^{3}$, respectively.

The lateral forces acting on the pile varied with the reservoir water level fluctuations and rainfall amounts. When the water level in the Yuanshui River remained constant at $175 \mathrm{~m}$ when combined with the rainfall amount during the storage period (case 1), the upper lateral force reached a peak value of $1484.7 \mathrm{kN}$ because of the large seepage force produced by the large volume of the slide mass below the phreatic surface. The lower lateral force also reached a peak value of $1115.4 \mathrm{kN}$, because the majority the lower slide mass was submerged, and no seepage force was acting on the mass (Table 5).

The upper and lower lateral forces were 1464.1 and $637.1 \mathrm{kN}$, respectively, when the reservoir water level maintained a minimum value of $155 \mathrm{~m}$ when combined with the rainfall amount during the flood period (Table 5). Compared with case 1 , the upper lateral force in case 2 slightly decreased, because higher rainfall amount can increase the seepage force. A lower phreatic surface can decrease the seepage force, and both influences are almost 
equivalent. The lower lateral force sharply decreased because of the considerable increase in the seepage force.

The upper lateral force decreased to $1247.5 \mathrm{kN}$, while the lower lateral force reached a minimum value of $244.6 \mathrm{kN}$ when the water level dropped from $175 \mathrm{~m}$ to $155 \mathrm{~m}$ when combined with the rainfall amount during the water supply period (case 3) (Table 5). Of all cases, the smallest forces were measured in case 3 because the smallest target FOS was selected in this case. However, this case showed the largest difference between the two forces, because the simultaneous decrease in the water level and rainfall resulted in the greatest inclination of the phreatic surface in the lower slide mass.

The lateral forces from the present study and those of Yamin and Liang [24] and Zhou et al. [25] were also compared in Table 5. The proposed method was developed not only to estimate the upper lateral forces acting on a stabilizing pile but also the lower lateral resistance forces. The values of the lower lateral resistance forces accounted for $75.1 \%, 43.5 \%$, and $19.6 \%$ of the upper lateral forces for cases 1,2 , and 3 , respectively. The present study can be used to optimize the design of stabilizing piles by considering the lower lateral resistance forces.

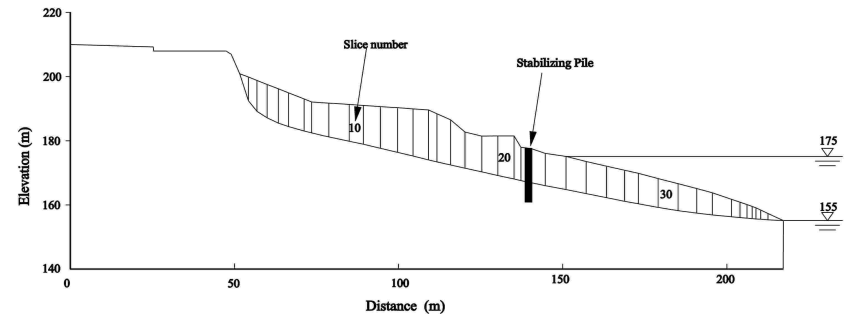

Fig. 11. Slices of the Xiatudiling landslide

Tab. 5. Comparison of the lateral forces from the present study with those from Yamin and Zhou

\begin{tabular}{|c|c|c|c|c|c|}
\hline \multirow{2}{*}{$\begin{array}{l}\text { Reservoir water } \\
\text { level and rainfall }\end{array}$} & \multicolumn{2}{|c|}{ Target safety factors } & \multirow{2}{*}{$\begin{array}{c}\text { Yamin and Liang [24] } \\
\text { and Zhou et al. [25] } \\
\text { Upper lateral force }(\mathrm{kN})\end{array}$} & \multicolumn{2}{|c|}{ Present study } \\
\hline & $\begin{array}{l}\text { Upper slide } \\
\text { mass }\end{array}$ & $\begin{array}{c}\text { Lower slide } \\
\text { mass }\end{array}$ & & $\begin{array}{l}\text { Upper lateral force } \\
(\mathbf{k N})\end{array}$ & $\begin{array}{c}\text { Lower lateral resistance force } \\
\qquad(\mathrm{kN})\end{array}$ \\
\hline Case 1 & 1.2 & 1.0 & 1484.7 & 1484.7 & 1115.4 \\
\hline Case 2 & 1.2 & 1.0 & 1464.1 & 1464.1 & 637.1 \\
\hline Case 3 & 1.15 & 1.0 & 1247.5 & 1247.5 & 244.6 \\
\hline
\end{tabular}

\section{Conclusions}

To evaluate the lateral forces accurately, a novel method based on the limit equilibrium approach was developed to estimate the lateral forces acting on a stabilizing pile segment above the slip surface of a landslide. A case study was analyzed to compare the forces acting on the stabilizing piles obtained by traditional and proposed methods. The following conclusions could be drawn:

(1) The target FOSs of the upper slide mass mainly depend on the landslide stabilization rank, reservoir water level, and rainfall conditions. The lower lateral resistance force reaches a maximum value when the lower slide mass reaches a state of limit equilibrium.

(2) The lateral forces acting on the pile dynamically change with the reservoir water level and rainfall amount. The results from a case study indicates that the upper and lower lateral resistance forces simultaneously reached their peak values when the maximum water level on the front edge of landslide was retained and combined with the rainfall amount during the storage period. The largest difference between the two forces was observed when the water level dropped from high water level to low water level when combined with the rainfall amount during the water supply period.

(3) The resistance of the lower slide mass markedly influences the lateral forces acting on the stabilizing pile. In the three selected cases, the lower part provided a massive resistance force. Therefore, the proposed method can be used to optimize the design of stabilizing piles by considering the lower lateral resistance force.

Thus, the lower lateral resistance force and seepage forces of groundwater are considered in the proposed method to more accurately evaluate the lateral forces. However, these forces are influenced by many factors, and the proposed method is limited to considering the effect of fluctuations in rainfall and reservoir water level. More influencing factors should be considered in future studies.

\section{Acknowledgments}

This work was supported by the National Natural Science Foundation of China (No. 41572289) and the Scientific Research Foundation for the Returned Overseas Chinese Scholars, State Education Ministry.

\section{References}

1. Barla, G., Antolini, F., Barla, M., "Slope stabilization in difficult conditions: the case study of a debris slide in NW Italian Alps". Landslides, 10(3), 2013, pp. 343-355.

2. Song, H., Cui, W., "A large-scale colluvial landslide caused by multiple factors: mechanism analysis and phased stabilization". Landslides, 13(2), 2016, pp. 321-335.

3. Usluogullari, O. F., Temugan, A., Duman, E. S., "Comparison of slope stabilization methods by three-dimensional finite element analysis". Natural Hazards, 81(2), 2016, pp. 1027-1050.

4. He, Y., Hazarika, H., Yasufuku, N., Teng, J., Jiang, Z., Han, Z., "Estimation of lateral force acting on piles to stabilize landslides". Natural Hazards, 79(3), 2015, pp. 1981-2003.

5. Kahyaoglu, M. R., Imançli, G., Önal, O., Kayalar, A. S., "Numerical analyses of piles subjected to lateral soil movement". KSCE Journal of Civil Engineering, 16(4), 2012, pp. 562-570.
6. Luo, Y., Xu, Q., He, S. M., Li, X. P., He, J. C., Wu, Y., “A new method to calculate lateral force acting on stabilizing piles based on multi-wedge translation mechanism". Journal of Central South University, 22, 2015, pp. 654-661.

7. Yang, T., Zhou, D., Zhang, J., Feng, J., "Distribution of land-slide thrust on anti-slide piles". Chinese Journal of Geotechnical Engineering, 28(3), 2006, pp. 322-326 (in Chinese).

8. Kahyaoğlu, M. R., Onal, O., Imançlı, G., Ozden, G., Kayalar, A. Ş., "Soil arching and load transfer mechanism for slope stabilized with piles". Journal of Civil Engineering and Management, 18(5), 2012, pp. 701-708.

9. Richards, D. J., Wiggan, C. A., Powrie, W., "Seepage and pore pressures around contiguous pile retaining walls". Géotechnique, 66(7), 2016, pp. 523-532. 
10. Zhou, C., "Research on the design of anti-slide pile in Wan Zhou City of Three Gorges area". Ph.D dissertation of China University of Geosciences, 2007, pp. 1-2 (in Chinese).

11. Ito, T., Matsui, T., "Methods to estimate lateral force acting on stabilizing piles". Soils and Foundations, 15(4), 1975, pp. 43-59

12. Hassiotis, S., Chameau, J. L., Gunaratne, M., "Design method for stabilization of slopes with piles". Journal of Geotechnical and Geoenvironmental Engineering, 123 (4), 1997, pp. 314-323.

13. Hokmabadi, A. S., Fakher, A., Fatahi, B., "Full scale lateral behaviour of monopiles in granular marine soils". Marine Structures, 29(1), 2012, pp. 198-210.

14. Ashour, M., Ardalan, H., "Analysis of pile stabilized slopes based on soil-pile interaction". Computers and Geotechnics, 39, 2012, pp. 85-97.

15. Liang, R., Zeng, S., "Numerical study of soil arching mechanism in drilled shafts for slope stabilization". Soils and Foundations, 42(2), 2002, pp. 83-92.

16. Dai, Z., "Study on distribution laws of landslide-thrust and resistance of sliding mass acting on antislide piles". Chinese Journal of Rock Mechanics and Engineering, 21(4), 2002, pp. 517 521 (in Chinese)

17. Tang, H., Hu, X., Xu, C., Li, C., Yong, R., Wang, L., “A novel approach for determining landslide pushing force based on landslide-pile interactions”. Engineering Geology, 182, 2014, pp. 15-24.

18. Poulos, H. G., "Design of reinforcing piles to increase slope stability". Canadian Geotechnical Journal, 32(5), 1995, pp. 808 818 .

19. Pan, J. L., Goh, A. T. C., Wong, K. S., The, C. I., "Ultimate Soil Pressures for Piles Subjected to Lateral Soil Movements". Journal of Geotechnical and Geoenvironmental Engineering, 128(6), 2002. pp. 530-535.

20. Mujaha, D., Ahmadb, F., Hazari, H., Watanabe, N., "The design method of slope stabilizing piles: a review". International Journal of Current Engineering and Technology, 3(2), 2013, pp. 224-229.
21. Kourkoulis, R., Gelagoti, F., Anastasopoulos, I., Gazetas, G., "Hybrid Method for Analysis and Design of Slope Stabilizing Piles". Journal of Geotechnical and Geoenvironmental Engineering, 138(1), 2011, pp. 1-14.

22. Salgado, R., Tehrani, F. S., Prezzi, M., "Analysis of laterally loaded pile groups in multilayered elastic soil". Computers and Geotechnics, 62, 2014, pp. 136-153.

23. Rani, S., Prashant, A., "Estimation of the linear spring constant for a laterally loaded monopile embedded in nonlinear soil". International Journal of Geomechanics, 15(6), 2014, pp. 04014090.

24. Yamin, M., Liang, R. Y., "Limiting equilibrium method for slope/drilled shaft system". International Journal for Numerical and Analytical Methods in Geomechanics, 34(10), 2010, pp. 1063 1075.

25. Zhou, C., Shao, W., Westen, C., "Comparing two methods to estimate lateral force acting on stabilizing piles for a landslide in the Three Gorges Reservoir, China". Engineering Geology, 173, 2014, pp. 41-53.

26. Li, L., Liang, R. Y., "Limit equilibrium based design approach for slope stabilization using multiple rows of drilled shafts". Computers and Geotechnics, 59, 2014, pp. 67-74.

27. Command of Prevention and Control of Geological Disasters in Three Gorges Reservoir Area. "Technical requirements of design for geological disaster prevention project in the Three Gorges reservoir area". Wuhan: China University of Geosciences Press, 2014, pp. 3-5 (In Chinese).

28. Abramson, L., Lee, T., Sharma, S., Boyce, G., "Slope Stability and Stabilization Methods (second edition)". New York: John Wiley, 2002, pp. 358-359.

29. Griffis, V. W., Stedinger, J. R., "Log-Pearson Type 3 Distribution and Its Application in Flood Frequency Analysis. I: Distribution Characteristics". Journal of Hydrologic Engineering, 12(5), 2007, pp. 482-491.

30. Griffis, V. W., Stedinger, J. R., "Log-Pearson Type 3 Distribution and Its Application in Flood Frequency Analysis. II: Parameter Estimation Methods. Journal of Hydrologic Engineering, 12(5), 2007 ,

pp.492-500 